\title{
Suicide after Excimer Laser Refractive Surgery: On the Importance of Matching Expectations
}

\author{
Gysbert van Setten \\ St Eriks Eye Hospital, Karolinska Institutet, Stockholm, Sweden \\ Email: gysbert-botho.vansetten@sankterik.se
}

Received 23 June 2015; accepted 25 August 2015; published 28 August 2015

Copyright (C) 2015 by author and Scientific Research Publishing Inc.

This work is licensed under the Creative Commons Attribution International License (CC BY). http://creativecommons.org/licenses/by/4.0/

(c) (i) Open Access

\begin{abstract}
Background: Refractive surgery may change the individual life to the better largely eliminating the need for spectacles. However, expectations may vary and postoperative reality may come as a surprise. Aim: To emphasize the need for thorough alignment of expectations and options between surgeon and patient. Methods: A case is presented in which a successful refractive laser operation is a part of a trigger mechanism for a depressive episode leading to suicide. It emphasizes the crucial importance of constructive alignment of expectations between patient and treating physician prior to surgery. Results: The case presented outlines that ophthalmic surgery at the edge of high-tec with all its tempting features is also very attractive to individuals with very well defined and less flexible expectations. The possible irreversibility of some of the refractive surgery may force the patient postoperatively into a psychological corner, immobilizing him/her and restricting his/her options. Conclusions: High-tec operations dealing with one of the most elementary senses we have, vision, demand a thorough estimation of the patients profile prior to any surgery. Only matching expectations between the possible and desired outcome and reconfirmation of the match may reduce the risk of postoperative crisis which may carry a risk the patient's life.
\end{abstract}

\section{Keywords}

Suicide, Excimer Laser Surgery, Ophthalmology, Refractive Surgery

\section{Introduction}

It is known that some ocular diseases such as glaucoma, chronic inflammation and decreased visual acuity may lead to depression [1]-[5]. Depression is known to possibly lead to suicide attempts. However, suicide attempts 
following ophthalmic surgery are the exception as no such case has (to the best knowledge of the author) this far been reported. Excimer surgery has been accepted very well by suitable patients and the success rate is very high [6]. However, the persons undergoing excimer laser surgery have often high expectations and the demand for a successful outcome is imminent. Hence, the current draw backs of excimer laser surgery such as halos, glares etc. often cause more discomfort that the bare clinical picture would allow to expect. As commonly known, such side effects are mostly temporary. However, an extremely rare but very severe incident after excimer laser surgery has been observed which has not been reported earlier.

\section{The Case}

A young patient, age 33 (altered in order to protect the identity of the individual), was operated on both eyes for the existing myopia with excimer laser. There was a history of a period with psychological instability many years ago and the patient had received psychiatric consultancy that successfully solved the crisis. A few weeks after an uneventful excimer laser surgery the patient appeared at the emergency ward of an ophthalmological clinic. The patient was deeply depressive due to the result of the operation which resulted in emmetropia. Having missed the myopic condition the patient wanted the same to be reinstalled. This was attempted to be achieved by buying hyperopic contact lenses via internet, without achieving the desired result. The patient had in the meantime also consulted a psychiatrist who tried to help him accept the new conditions of sight. The ophthalmological examination showed a visual acuity of $16 / 20$ on the right and 20/20 on the left eye without correction. The cornea showed only minor traces of the recently performed operation which clinically has led to the desired outcome. The patient complained of dryness and irritation and was prescribed lubricating drops and ointments. Such complaint has been increasingly reported after excimer laser surgery but is still considered to be transient. Dry eye complaints and effects themselves are known to have a negative effect on the quality of life [7].

However, a few weeks passed until the patient presented himself again at the eye clinic again at night in an acute stage of depression due to the refractive condition achieved complaining that the current situation as interfering with working capacity and capability. The visual acuity was the same and reading at distance was achieved with an addition of +1.75 dpt. It was considered that a possible overcorrection towards hyperopia has been the cause of the patients complaint but the refraction in cycloplegia showed a nearly perfect condition close to emmetropic condition with an astigmatism not exceeding $-0.75 \mathrm{dpt}$. After a long discussion the patient relaxed and could be convinced that the problem could be solved by fitting suitable spectacles after an appointment with an ophthalmologist or an optician. The patient left the clinic in a condition that was considered psychologically stabilized. However, the patient appeared again a few weeks later, again during midnight hours, and again in a depressive state and after having consumed alcohol. There was not yet any further arrangement for an appointment with the ophthalmologist but the patient promised to return to arrange this at working hours to make this visit happen. Concerned about the psychological state, psychological consultancy was offered to the patient. This offer was declined by the patient saying that such a visit happened just the day before. The patient left the clinic with the promise to come back next morning to get the specialist consultancy performed.

The patient never came back. Instead, the author was informed some weeks later that the patient had committed suicide.

\section{Discussion}

Although depression has been considered the main cause of this suicide, it can not be excluded that desperation about the clinical outcome of the refractive surgery might have been one element in the decision process.

Although an event like this is extremely rare, the impact to the social environment and the importance for the ophthalmological surgeons is so high that I feel urged to convey this event to the ophthalmologic and medical community in order to emphasize the extremely important role of the preoperative evaluation of motivation and indication for refractive surgery. A number of factors and variables that do not usually come together like they did in this case could have certainly played a role the case presented. The decision behind a suicide seldom based on one event only although this does depends on the impact the event has or the impact value as it is perceived by the patient. However, it is strongly suggested that any patient with the history of psychological treatment or consultation in the past, no matter how long before this might have been, should receive a psychological evaluation before any refractive surgery is performed. After all are amongst the predictors of suicide male gen- 
der, mental illness, and ongoing or previous psychiatric treatment [8] (Nordentoft 2007). As this tragic case shows, our psychological understanding and training as ophthalmologists is probably not always sufficient enough to judge if this type of surgery is suitable for this special category of patients. Hence, if there is any indicator of mental illness, further tests currently available [9] (Terluin et al. 2009), should be applied by professionals prior to any treatment.

\section{Conclusion}

If there is any suspicion that the expectations of surgical outcome and the definition of success of both patient and surgeon do not completely match, no surgery should be performed. Extensive counselling and inculcating realistic expectations prior to excimer surgery have been recommended earlier [10]. The nature of refractive surgery as a voluntary procedure does emphasize the need for sufficient and thorough information on all known and the individual aspects of the procedure. For any individual with high demands and having a history of psychological weakness, any outcome worse than expected can be devastating. The importance of the occupation in the gap between expectations and perceptions has been reported [11]. It is strongly recommended to alter the selection of patients for excimer surgery giving higher value to the psychological background and considering any history of psychological abnormality as a relative contraindication for excimer laser treatment. Although extremely rare, this case shows what surgery might lead to, when the patient's expectations are not fully understood.

\section{Commercial Interests}

Commercial Interests: None.

\section{Acknowledgements}

The author is very thankful to Aviation-Ophthalmology, Danderyd, Sweden for the support allowing the publiccation of this manuscript.

\section{References}

[1] Mabuchi, F., Yoshimura, K., Kashiwagi, K., Shioe, K., Yamagata, Z., Kanba, S., Iijima, H. and Tsukahara, S. (2008) High Prevalence of Anxiety and Depression in Patients with Primary Open-Angle Glaucoma. Journal of Glaucoma, 17, 552-557. http://dx.doi.org/10.1097/IJG.0b013e31816299d4

[2] Popescu, M.L., Boisjoly, H., Schmaltz, H., Kergoat, M.J., Rousseau, J., Moghadaszadeh, S., Djafari, F. and Freeman, E.E. (2012) Explaining the Relationship between Three Eye Diseases and Depressive Symptoms in Older Adults. Investigative Ophthalmology \& Visual Science, 53, 2308-2313. http://dx.doi.org/10.1167/iovs.11-9330

[3] Wang, S.Y., Singh, K. and Lin, S.C. (2012) Prevalence and Predictors of Depression among Participants with Glaucoma in a Nationally Representative Population Sample. American Journal of Ophthalmology, 154, 436-444. http://dx.doi.org/10.1016/j.ajo.2012.03.039

[4] Maca, S.M., Wagner, J., Weingessel, B. and Vécsei-Marlovits, P.V. (2013) Acute Anterior Uveitis Is Associated with Depression and Reduction of General Health. British Journal of Ophthalmology, 97, 333-337. http://dx.doi.org/10.1136/bjophthalmol-2012-302304

[5] Li, M., Gong, L., Sun, X. and Chapin, W.J. (2011) Anxiety and Depression in Patients with Dry Eye Syndrome. Current Eye Research, 36, 1-7. http://dx.doi.org/10.3109/02713683.2010.519850

[6] McAlinden, C., Skiadaresi, E. and Moore, J.E. (2011) Visual and Refractive Outcomes Following Myopic Laser-Assisted Subepithelial Keratectomy with a Flying-Spot Excimer Laser. Journal of Cataract \& Refractive Surgery, 37, 901-906. http://dx.doi.org/10.1016/j.jcrs.2011.01.013

[7] Li, M., Gong, L., Chapin, W.J. and Zhu, M. (2012) Assessment of Vision-Related Quality of Life in Dry Eye Patients. Investigative Ophthalmology \& Visual Science, 53, 5722-5727. http://dx.doi.org/10.1167/iovs.11-9094

[8] Nordentoft, M. (2007) Prevention of Suicide and Attempted Suicide in Denmark. Epidemiological Studies of Suicide and Intervention Studies in Selected Risk Groups. Danish Medical Bulletin, 54, 306-369.

[9] Terluin, B., Brouwers, E.P., van Marwijk, H.W., Verhaak, P. and van der Horst, H.E. (2009) Detecting Depressive and Anxiety Disorders in Distressed Patients in Primary Care; Comparative Diagnostic Accuracy of the Four-Dimensional Symptom Questionnaire (4DSQ) and the Hospital Anxiety and Depression Scale (HADS). BMC Family Practice, 10, 58. http://dx.doi.org/10.1186/1471-2296-10-58 
[10] Shah, S., Perera, S. and Chatterjee, A (1998) Satisfaction after Photorefractive Keratectomy. Journal of Refractive Surgery, 14, S226-S227.

[11] Lin, D.J., Sheu, I.C., Pai, J.Y., Bair, A., Hung, C.Y., Yeh, Y.H. and Chou, M.J. (2009) Measuring Patient's Expectation and the Perception of Quality in LASIK Services. Health and Quality of Life Outcomes, 7, 63.

http://dx.doi.org/10.1186/1477-7525-7-63 